\title{
Efeito da temperatura interpasse na microestrutura, tenacidade ao impacto e propagação de trinca por fadiga de uniões soldadas por GTAW do aço ASTM A743-CA6NM
}

\author{
(Interpass temperature influence on the microstructure, impact toughness and fatigue crack propagation in ASTM A743- \\ CA6NM GTAW welded joints)
}

\author{
Ruimar Rubens de Gouveia ${ }^{(1)}$, Anderson Geraldo Marenda Pukasiewicz ${ }^{\left(1^{*}\right)}$, André Ricardo Capra ${ }^{(2)}$, Sérgio Luiz Henke ${ }^{(3)}$, Paulo \\ Cesar Okimoto ${ }^{(3)}$ \\ ${ }^{1}$ UTFPR, Universidade Tecnológica Federal do Paraná, Campus Ponta Grossa, Coordenação de Mecânica, Ponta Grossa, Paraná, \\ Brasil ruimar@utfpr.edu.br, anderson@utfpr.edu.br \\ ${ }^{2}$ LACTEC, Instituto de Tecnologia para o Desenvolvimento, Curitiba, Paraná, Brasil, andre.capra@lactec.org.br \\ ${ }^{3}$ UFPR, Universidade Federal do Paraná, Departamento de Engenharia Mecânica, Curitiba, Paraná, Brasil, henke@ufpr.br, okimoto@, \\ ufpr.br
}

\section{Resumo}

Atualmente os aços inoxidáveis martensíticos tem sido utilizados para a fabricação de turbinas hidráulicas, devido principalmente a sua elevada tenacidade. Entretanto, estes aços apresentam algumas restrições com relação à regiões recuperadas por soldagem, principalmente em razão da formação de martensita não revenida, a qual gera redução na tenacidade. Considerando as aplicações de reparo de turbinas hidráulicas, há grande interesse em desenvolver procedimentos de soldagem que elevem a tenacidade ao impacto e evitem os tratamentos térmicos pós-soldagem (TTPS). O presente trabalho busca analisar a influência da temperatura de interpasse na microestrutura, tenacidade ao impacto e propagação de trincas por fadiga nas uniões soldadas multipasse do aço inoxidável martensitico CA6NM usando AWS410NiMo como metal de adição, e processo TIG (tungsten inert gas). Observou-se a influência da temperatura de interpasse na formação de ferrita $\delta$, com formação intergranular no campo bifásico $\delta+\gamma$, na amostra com temperatura interpasse de $80^{\circ} \mathrm{C}$, enquanto que na amostra soldada a $150^{\circ} \mathrm{C}$ a formação de ferrita $\mathrm{d}$ ocorreu principalmente no campo monofásico. A alteração na formação da ferrita d, com a menor temperatura, promoveu um aumento na tenacidade ao impacto e uma diminuição na velocidade de propagação de trinca, quando comparada com a amostra soldada com maior temperatura de soldagem. Os resultados obtidos indicam que o processo TIG apresenta-se como uma excelente alternativa para o reparo do aço CA6NM, observando-se também uma influência significativa da temperatura de interpasse.

Palavras-chave: propagação de trincas por fadiga, aço inoxidável martensítico macio, tenacidade ao impacto

\begin{abstract}
Martensitic stainless steels have been used for hydraulic turbines manufacturing, because its high toughness. However, these steels have some restrictions regarding regions recovered by welding, mainly by non-tempered martensite formation, promoting toughness reduction. Concerning hydraulic turbine repairs, there is a great interest in welding procedures development that promotes a better toughness, without post welding heat treatment (PWHT). The mainly objective of this paper is analyze the influence of interpass temperature on the microstructure, impact toughness and fatigue crack propagation in CA6NM martensitic stainless steel multipass welded joints, with AWS410NiMo filler metal, with GTAW (gas tungsten arc welding). It was observed the interpass temperature influence on ferrite $\delta$ formation, observing intergranular ferrite $\delta$ formation on the $\delta+\gamma$ field in $80{ }^{\circ} \mathrm{C}$ interpass temperature, while the sample welded at $150{ }^{\circ} \mathrm{C}$ the formation of ferrite $\mathrm{d}$ occurs mainly in the $\delta$ monophase field. Ferrite $\mathrm{d}$ formation with the lowest temperature interpass promoted an increase in impact toughness and a decrease in the fatigue crack propagation when compared with $150^{\circ} \mathrm{C}$ interpass temperature sample. It was observed that GTAW process can be an excellent alternative for CA6NM hydraulic turbine repair, it was also observed a significant interpass temperature influence.
\end{abstract}

Key words: fatigue crack propagation, soft martensitic stainless steel, impact toughness

\section{Introdução}

O modelo energético brasileiro se baseia na utilização de

Recebido em 13/09/2012. Texto final em 30/01/2013. energia elétrica gerada por hidroelétricas, as quais utilizam diferentes tipos de turbinas hidráulicas. Fabricadas através de fundição e soldagem, as turbinas hidráulicas são sujeitas a uma 
combinação de fadiga de baixo ciclo - a partir da operacão de início e parada, e fadiga de alto ciclo, devido à flutuação hidráulica e ciclos de vibração, combinado com elevadas cargas estáticas. Considerando as cargas operacionais de serviço, trincas podem se formar em locais contendo defeitos de fabricação, e se propagar quando a carga excede o limite de propagação de trincas por fadiga [1].

Com o objetivo de obter o equilíbrio entre a integridade, desempenho mecânico e de custo, os projetistas de turbinas possuem ferramentas para previsão confiável do avanço de trincas por fadiga. $\mathrm{O}$ tamanho de trinca por fadiga e a taxa de crescimento da trinca pode ser estimada pela mecânica da fratura linear elástica, podendo proporcionar o campo de tensões e calcular o fator intensidade durante a propagação da trinca [1].

Os materiais utilizados na fabricação das turbinas tem sido alvo constante de pesquisa e desenvolvimento. A partir da década de 60 têm sido utilizados aços inoxidáveis martensíticos macios contendo de 12 a $13 \%$ de cromo, de 2 a $5 \%$ de níquel e menos que $0,06 \%$ de carbono na construção de turbinas hidráulicas [1]. Estes aços apresentam elevada tensão de escoamento e tenacidade, elevada resistência à cavitação e razoável soldabilidade. Os aços martensíticos com baixo teor de carbono, como o aço CA6NM, são sempre temperados e revenidos [2]. A excelente tenacidade destes aços deve-se principalmente a formação de uma dispersão fina de austenita a partir do tratamento de revenido da martensita em temperaturas da ordem de $600^{\circ} \mathrm{C}[3]$.

Durante o processo de fabricação de turbinas hidráulicas em aço CA6NM, as pás são fundidas e unidas à coroa por soldagem, sendo utilizado neste processo metais de adição de composição química similar ao metal base. Utiliza-se uma temperatura de pré-aquecimento e interpasse na faixa de $150^{\circ} \mathrm{C}$, passando por um tratamento térmico pós-soldagem a $600^{\circ} \mathrm{C}$, elevando o teor de austenita e melhorando a tenacidade da união soldada.

Mesmo apresentando boa soldabilidade e menores exigências com relação às temperaturas de pré-aquecimento e interpasse, o metal de solda (MS) e a zona termicamente afetada (ZTA) apresentam energia de impacto e tenacidade à fratura inferiores ao do metal base (MB). Em geral, estruturas soldadas apresentam comportamento inferior ao do metal base, pois o processo de soldagem determina profundas alterações microestruturais, tornando-as mais duras e frágeis. A redução na tenacidade a fratura de uniões soldas do aço CA6NM ocorre devido à redução no teor de austenita, assim como a formação de defeitos, como porosidade e inclusões [4].

Durante o processo de reparo das turbinas hidráulicas por soldagem, visando recuperar regiões trincadas ou superfícies cavitadas, verifica-se que a utilização de temperaturas de préaquecimento e interpasse de $150^{\circ} \mathrm{C}$ são realizados com alguma dificuldade, e que tratamentos térmicos pós-soldagem de $600^{\circ} \mathrm{C}$ são inviáveis. Assim sendo, o reparo destas turbinas é considerado crítico quando se utiliza metal de adição similar, pois a soldagem deve ser realizada sob condições limitadas [4].

Uma alternativa para o reparo de turbinas hidráulicas fabricadas com os aços martensíticos macios é o uso de materiais de adição austeníticos, os quais apresentam propriedades mecânicas satisfatórias mesmo sem tratamentos térmicos póssoldagem. Em estudos conduzidos com este aço, utilizando processo de soldagem por eletrodo revestido observou-se baixas propriedades mecânicas nas uniões soldadas com metal de adição martensítico, inviabilizando a sua utilização em reparos feitos em campo. Entretanto soldagens realizadas com ligas austeníticas apresentaram propriedades mecânicas mais adequadas [4].

Diversos estudos foram realizados visando avaliar a aplicação de metais de adição similares do tipo ER410NiMo [2-6], sendo os resultados de tenacidade ao impacto visualizados na Tabela 1. Observa-se que a tenacidade do metal de solda, varia em função do processo de soldagem aplicado, bem como da temperatura de pré-aquecimento e do percentual de $\mathrm{C}$ do arame utilizado.

Considerando o exposto, o objetivo deste trabalho é avaliar a influência da temperatura de interpasse na microestrutura, tenacidade ao impacto e velocidade de propagação de trinca por fadiga envolvendo metal de solda similar em uma aço inoxidável martensítico macio tipo CA6NM depositado por processo TIG sem TTPS (tratamento térmico pós-soldagem).

\section{Procedimento Experimental}

O material empregado neste trabalho foi o aço inoxidável martensítico macio CA6NM fundido, temperado ao ar a partir de $1050{ }^{\circ} \mathrm{C}$ e revenido a $580^{\circ} \mathrm{C}$, com resistência ao escoamento de $666 \mathrm{MPa}$ e máxima de $799 \mathrm{MPa}$, fornecido pela Voith Siemens. A composição química do metal base e do metal de adição utilizado é visualizada na Tabela 2.

As dimensões das peças soldadas são observadas na Figura 1 , sendo que este aspecto de corpo de prova foi definido com a intenção de simular as condições de preenchimento de falhas como trincas e regiões cavitadas observadas em turbinas hidráulicas. O processo de soldagem utilizado foi TIG com eletrodo de $2,4 \mathrm{~mm}$ de diâmetro contendo $2 \%$ de tório , e os parâmetros de soldagem empregados são listados na Tabela 3 .

Tabela 1 : Comparativo de tenacidade do metal de solda ER410NiMo

\begin{tabular}{|l|l|l|l|l|}
\hline Autor & $\begin{array}{l}\text { Temperatura } \\
\text { interpasse }\left({ }^{\circ} \mathrm{C}\right)\end{array}$ & $\begin{array}{l}\text { Tenacidade ao impacto } \\
\text { Charpy }(\mathrm{J})\end{array}$ & $\begin{array}{l}\text { Processo de Soldagem } \\
\text { Aplicado }\end{array}$ & $\begin{array}{l}\% \text { de Carbono no metal } \\
\text { de solda }\end{array}$ \\
\hline Bilmes [2] & Menor que 120 & 73 & FCAW & 0,028 \\
\hline Folkhard [3] & $130^{\circ} \mathrm{C}$ & 132 & GTAW & 0,018 \\
\hline Pereira [5] & Menor que $180^{\circ} \mathrm{C}$ & 50 & GMAW sólido & 0,036 \\
\cline { 3 - 5 } & & 34 & FCAW & Não avaliado \\
\hline Prado [6] & Entre 200 e $250^{\circ} \mathrm{C}$ & De 27 a 42 & GMAW sólido & Não avaliado \\
\hline
\end{tabular}


Efeito da temperatura interpasse na microestrutura, tenacidade ao impacto e propagação de trinca por fadiga de uniões soldadas por GTAW do aço ASTM A743CA6NM

Tabela 2. Composição Química

\begin{tabular}{|c|c|c|c|c|c|c|c|c|}
\hline & $\mathrm{f}(\mathrm{mm})$ & $\mathrm{C}(\mathrm{wt} \%)$ & $\mathrm{Mn}(\mathrm{wt} \%)$ & $\mathrm{Cr}(\mathrm{wt} \%)$ & $\mathrm{Ni}(\mathrm{wt} \%)$ & $\mathrm{Mo}(\mathrm{wt} \%)$ & $\mathrm{P}(\mathrm{wt} \%)$ & $\mathrm{S}(\mathrm{wt} \%)$ \\
\hline CA6NM & & 0,02 & 0,64 & 12,4 & 3,7 & 0,42 & 0,008 & 0,002 \\
\hline 410 NiMo GTAW & 2,5 & 0,017 & 0,42 & 12,1 & 4,4 & 0,49 & 0,023 & 0,001 \\
\hline
\end{tabular}

Tabela 3. Parâmetros de soldagem GTAW.

\begin{tabular}{|l|c|c|c|c|c|c|c|}
\hline & Tensão (V) & $\begin{array}{c}\text { Corrente } \\
(\mathrm{A})\end{array}$ & $\begin{array}{c}\text { Veloc. Soldagem } \\
(\mathrm{cm} / \mathrm{min})\end{array}$ & $\begin{array}{c}\text { Aporte térmico } \\
(\mathrm{kJ} / \mathrm{cm})\end{array}$ & $\begin{array}{c}\text { Gás de } \\
\text { proteção }\end{array}$ & $\begin{array}{c}\text { Fluxo de gás de } \\
\text { proteção }(1 / \mathrm{min})\end{array}$ & $\begin{array}{c}\text { Temperatura } \\
\text { interpasse }\left({ }^{\circ} \mathrm{C}\right)\end{array}$ \\
\hline GTAW1 & 15,6 & 170 & 4,5 & 24,75 & $\mathrm{Ar}$ & 17 & 80 \\
\hline GTAW2 & 15,6 & 170 & 4,5 & 24,75 & $\mathrm{Ar}$ & 17 & 150 \\
\hline
\end{tabular}
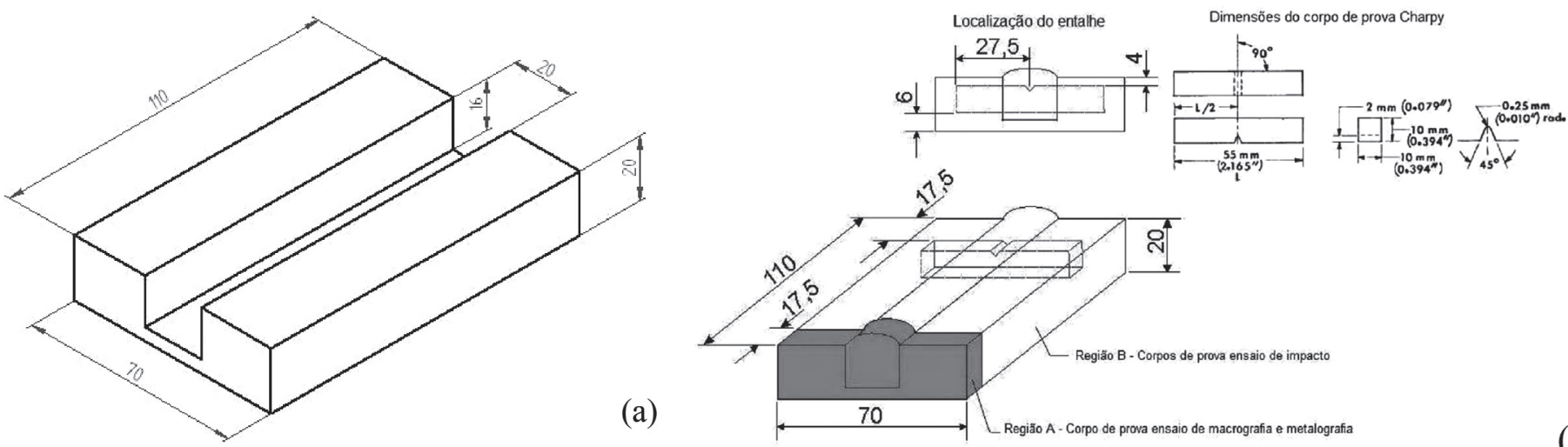

Figura 1. Dimensões do corpo de prova (a), e disposição do corpo de prova Charpy nas amostras soldadas (b), dimensões em (mm).
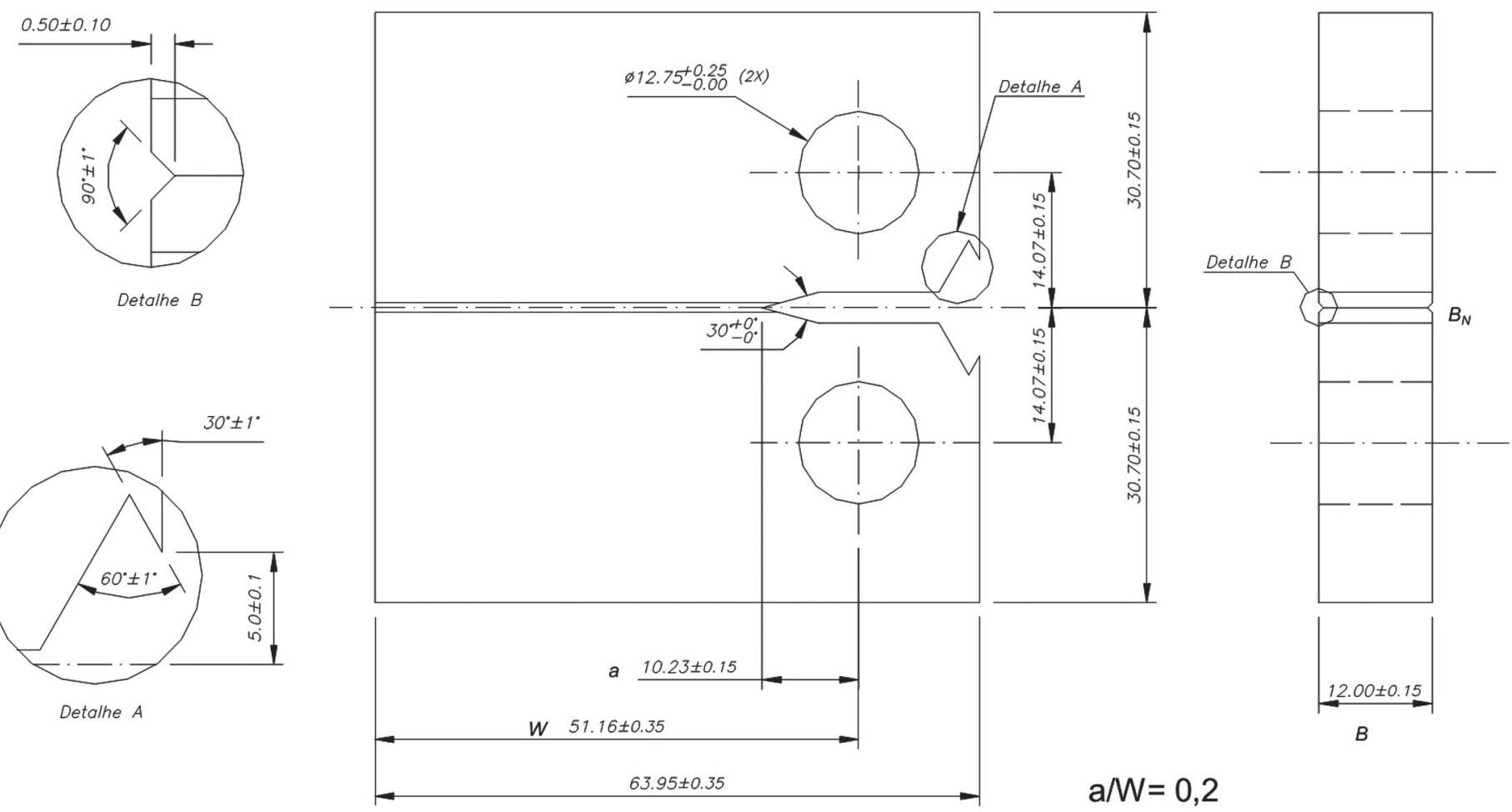

Figura 2. Dimensões do corpo de prova CT (mm). 
Tabela 4. Formulações e procedimentos utilizados na revelação da microestrutura [10].

\begin{tabular}{|l|l|l|l|}
\hline Reativo & Composição & Método & Objetivo \\
\hline Villela & $1 \mathrm{~g} \mathrm{C}_{4} \mathrm{H}_{3} \mathrm{OH}\left(\mathrm{NO}_{2}\right)_{3}$ & Imersão da amostra por 60 s & Revela martensita. \\
& $5 \mathrm{ml} \mathrm{HCl}$ & & \\
& $100 \mathrm{ml} \mathrm{C}_{2} \mathrm{H}_{6} \mathrm{OH}$ & Ataque eletrolítico a 4 v por $20 \mathrm{~s}$. & $\begin{array}{l}\text { Revela ferrita-delta } \\
\text { mas não martensita. }\end{array}$ \\
\hline Sulfúrico & $20 \mathrm{ml} \mathrm{H}_{2} \mathrm{SO}_{4}$ & & \\
& $0.01 \mathrm{~g} \mathrm{NH}_{4} \mathrm{CNS}$ & & \\
& $80 \mathrm{ml} \mathrm{H}_{2} \mathrm{O}$ & & \\
\hline
\end{tabular}

Para determinar as dimensões e tolerâncias dos corpos de prova para o ensaio de impacto Charpy, foi utilizada a norma ASTM E-23-99, sendo que foi utilizado uma temperatura de $20^{\circ} \mathrm{C}$ para a realização dos ensaios [7]. Primeiramente, o corpo de prova obtido foi cortado com um comprimento de aproximadamente $75 \mathrm{~mm}$, posteriormente foi usinado nas quatro faces até obter as dimensões especificadas de $10 \times 10$ $\mathrm{mm}$ representados na Figura 2. A localização do entalhe para o ensaio metal de solda foi determinada por meio de ataque macrográfico, seguindo as recomendações da norma AWS D1.1 (2004, p. 314) [8].

Os ensaios de crescimento de trinca por fadiga foram realizados de acordo com a norma ASTM E647-95 em uma máquina de ensaio dinâmico com acionamento servo hidráulico [9]. A frequência utilizada foi de $20 \mathrm{~Hz}$ em amplitude de carga constante e curva senoidal, com uma razão de tensão $\mathrm{R}$ igual a $0,1 \mathrm{e} \mathrm{W}$ igual a $51,16 \mathrm{~mm}$.

Os ensaios de taxa de crescimento de trinca por fadiga foram realizados em corpos de prova do tipo CT, Figura 3, utilizando entalhes laterais, side grooves, para garantir a propagação da trinca em um plano único. Para a avaliação do comportamento à fadiga da ZTA, colocou-se os side-grooves a uma distância de aproximadamente $1,0 \mathrm{~mm}$ da linha de fusão.

Após inspeção visual as amostras foram preparadas para caracterização metalográfica através das etapas de lixamento e polimento, sendo utilizadas lixas 220, 320, 400, 600 e 1200 mesh de carboneto de silício, seguido de polimento com suspensão de diamante $3,0 \mu \mathrm{m}$ e $0,25 \mu \mathrm{m}$. Para revelação da

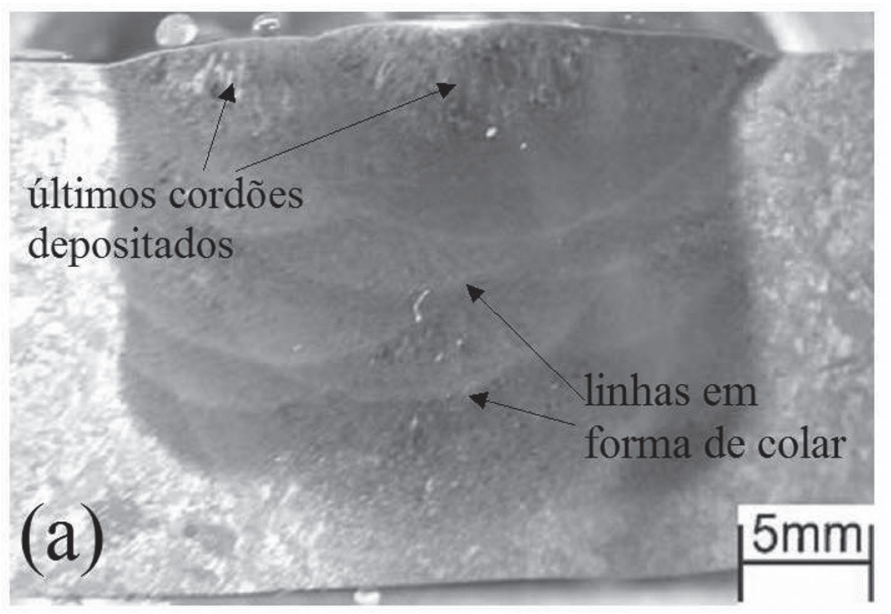

microestrutura foram utilizados reativos Vilella e ácido sulfúrico eletrolítico, Tabela 4. Para uma melhor análise, a união soldada foi dividida em três regiões (inferior, central e superior), Figura 3, possibilitando uma melhor avaliação metalográfica e de microdureza, da influência da temperatura de interpasse. $\mathrm{O}$ ensaio de microdureza foi realizado com carga de 300gf, conforme norma ASTM E384-99 [10].

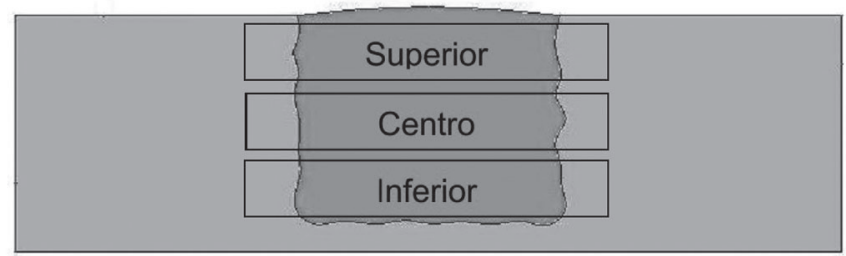

Figura 3. Regiões de avaliação metalográfica e de microdureza.

\section{Resultados e Discussões}

\subsection{Análise da microestrutura e do perfil de microdureza}

A Figura 4 apresenta as macrografias dos corpos de prova com diferentes temperaturas de interpasse de 80 e $150^{\circ} \mathrm{C}$. Numa análise inicial constatou-se que, independente da temperatura utilizada, ocorre a formação de linhas em forma de colar que separam as camadas de solda depositadas [11].

Devido aos ciclos térmicos originados pelos sucessivos cordões de preenchimento, observa-se que os cordões de solda

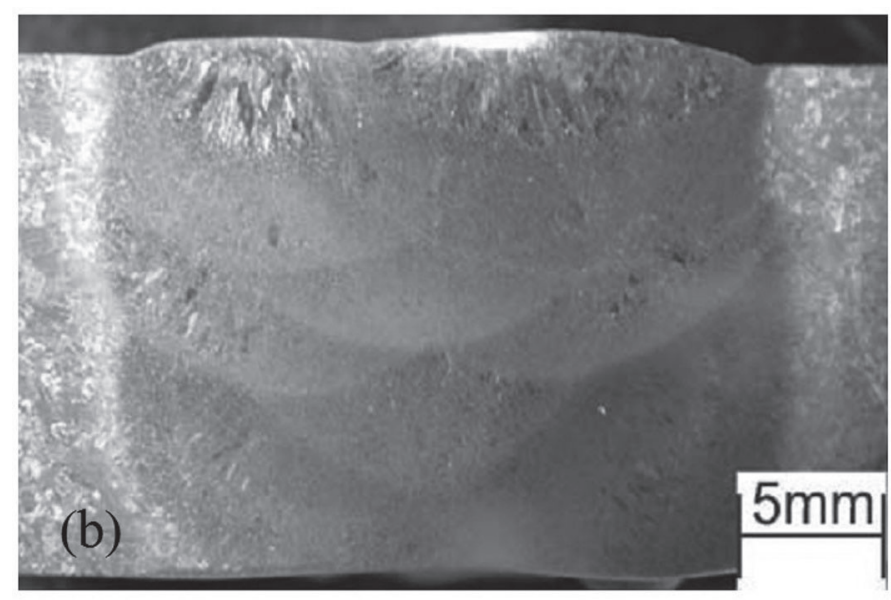

Figura 4. Macrografia das amostras soldadas com AWS410NiMo com diferentes temperaturas interpasse, (a) $80^{\circ} \mathrm{C}$ e (b) $150^{\circ} \mathrm{C}$. 

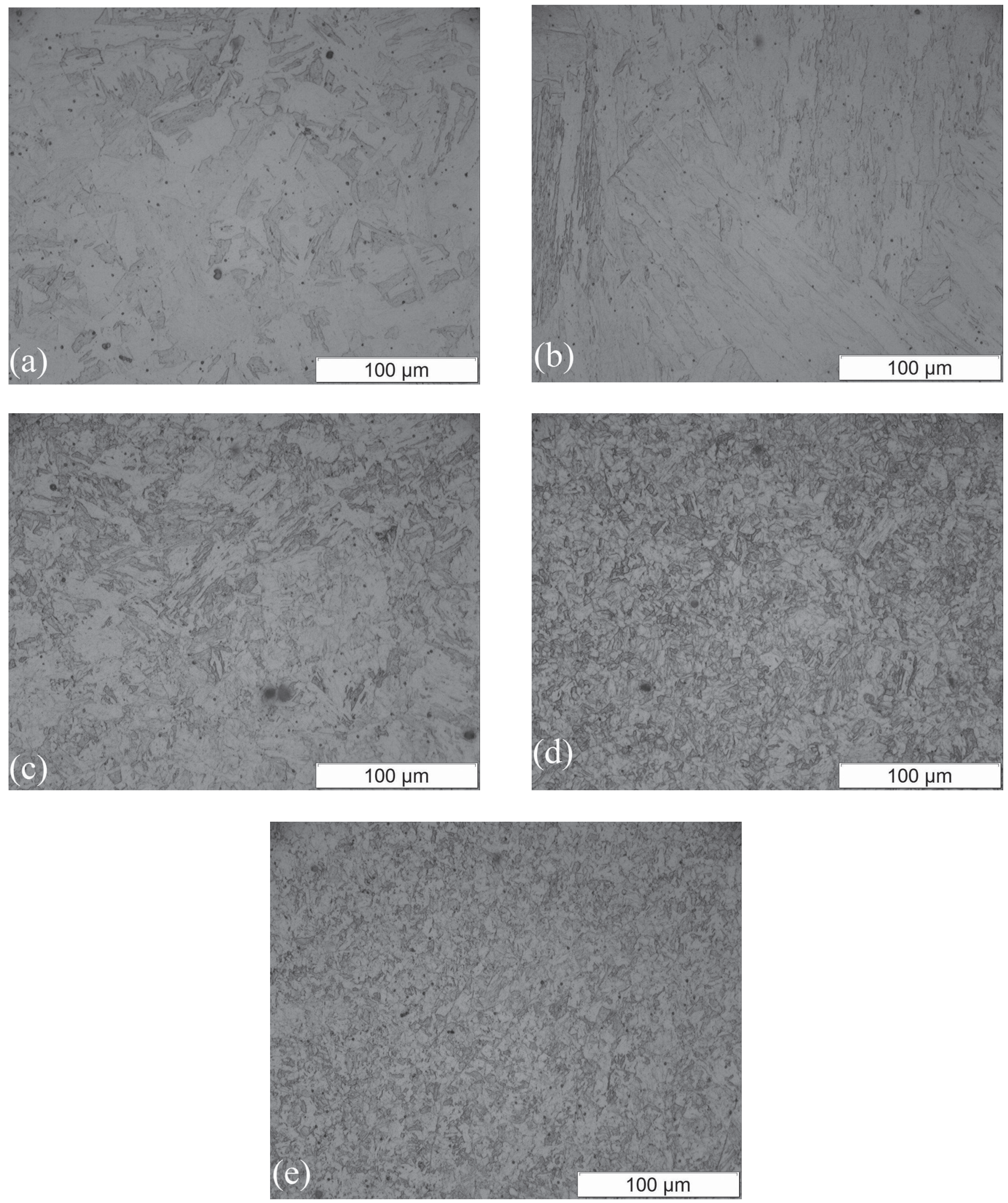

Figura 5. Microestrutura do depósito soldado AWS410 NiMo em diferentes temperaturas interpasse. Reativo Vilella, (a),(c) e (e) $80^{\circ} \mathrm{C}$, (b), (d) e (f) $150^{\circ} \mathrm{C}$, (a) e (b) região superior, (c) e (d) região central e (e) e (f) região inferior dos corpos de prova. 

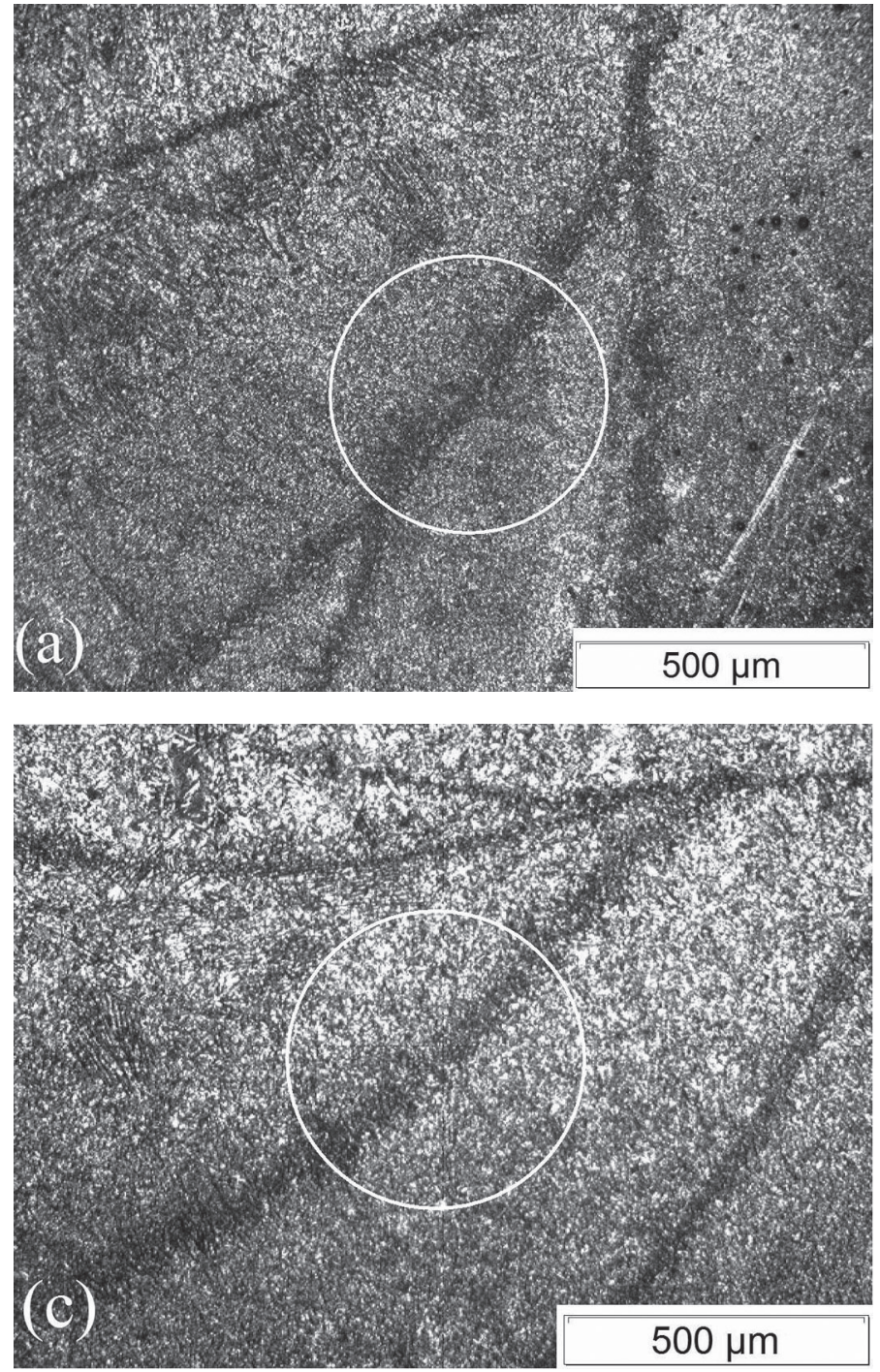
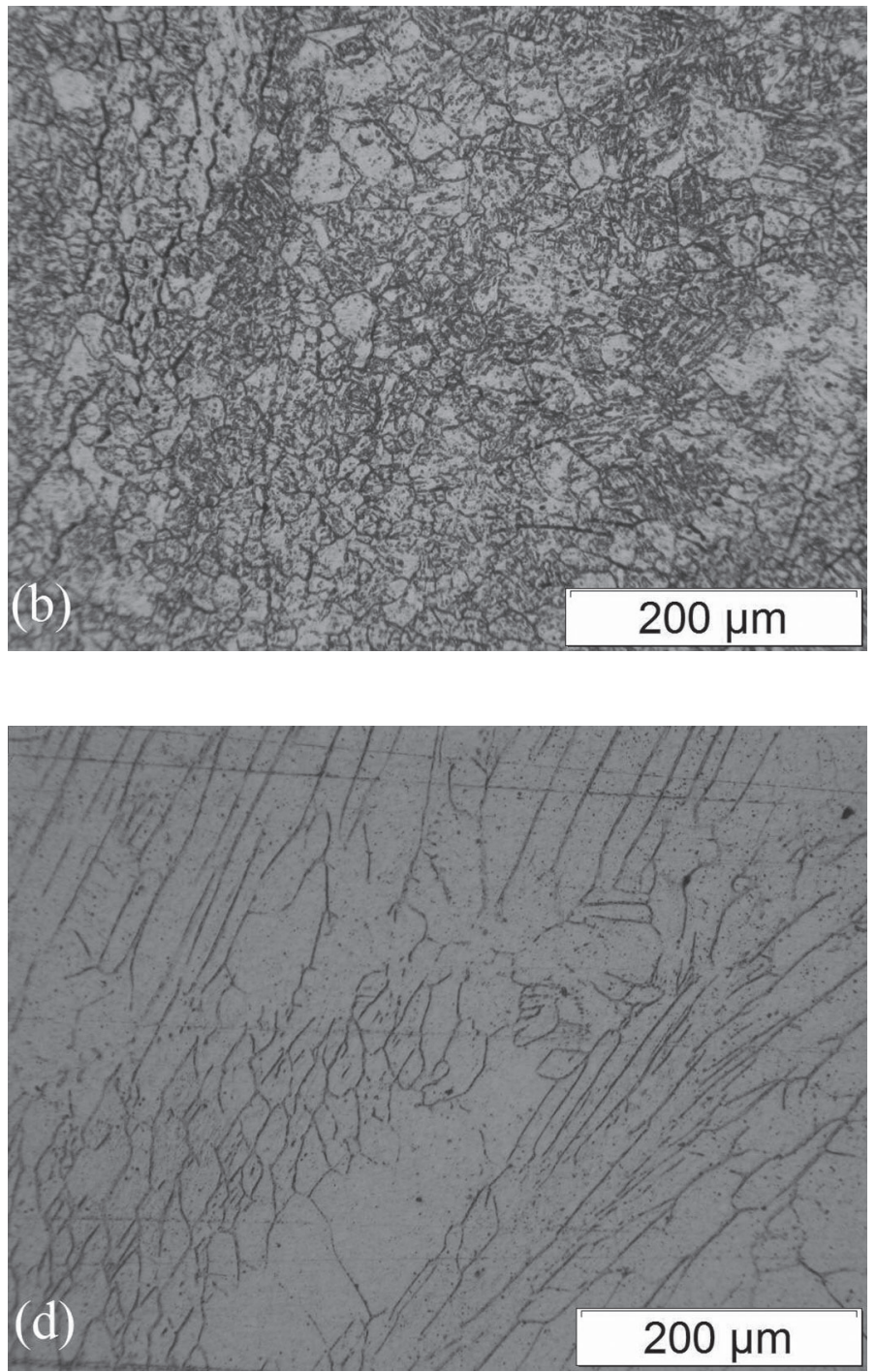

Figura 6. Bandas de formação bem como morfologia da ferrita $\delta$ das uniões soldadas com o aço AWS410 NiMo em diferentes temperaturas interpasse. Reativo Ácido Sulfúrico Eletrolítico. (a) e detalhe (c) Temperatura interpasse $80^{\circ} \mathrm{C}$ e (b) e detalhe (d) $150^{\circ} \mathrm{C}$.

da região superior apresentam um aspecto diferenciado dos cordões localizados nas regiões intermediária e inferior da região preenchida.

As micrografias das regiões superior, intermediária e inferior dos corpos de prova realizados com diferentes temperaturas interpasse podem ser observadas na Figura 5, sendo que em todas observa-se uma microestrutura martensítica. Observase, a partir destas Figuras, que os cordões de solda das regiões inferior e intermediária, apresentam uma microestrutura mais refinada, em comparação com os últimos cordões de solda depositados da região superior. Tal característica indica que a sequência de passes realizados influi na microestrutura final da junta soldada, onde os passes subsequentes refinam os passes anteriores devido ao ciclo térmico imposto.

O refino da microestrutura observada na Figura 5, ocorre pelo reaquecimento a temperaturas acima de $800^{\circ} \mathrm{C}$. Verificase, a esta temperatura, a formação de uma região monofásica austenita $\gamma$, que em virtude das elevadas taxas de resfriamento observadas na soldagem, promovem um refino da microestrutura em comparação aos últimos cordões depositados e ao metal base.

A presença da ferrita $\delta$ na forma de linhas de colar, em ambas as amostras, foi constatada próxima às linhas de fusão do metal de solda, conforme observado na Figura 6. A formação de ferrita $\delta$ neste material ocorre pelo reaquecimento do cordão de solda entre 1200 e $1300^{\circ} \mathrm{C}$, no campo bifásico austenita $\gamma+$ ferrita $\delta$, e entre 1300 e $1450^{\circ} \mathrm{C}$ no campo monofásico de ferrita $\delta$. Como pode ser observado na Figura 6(b), a formação de ferrita $\delta$ na amostra com temperatura interpasse de $80^{\circ} \mathrm{C}$ ocorre de forma intergranular, característico de formação no campo bifásico $\gamma+$ $\delta$, enquanto que a formação de ferrita $\delta$ no campo monofásico, formada entre placas de austenita de Widmanstätten, ocorre somente na amostra soldada com controle de temperatura interpasse de $150^{\circ} \mathrm{C}$, Figura 6(d) [11-13].

Esta formação diferenciada pode indicar que o aumento na temperatura de interpasse para $150^{\circ} \mathrm{C}$ elevou a temperatura de formação da ferrita $\delta$, assim como provavelmente diminuiu a taxa de resfriamento promovendo uma maior formação de 

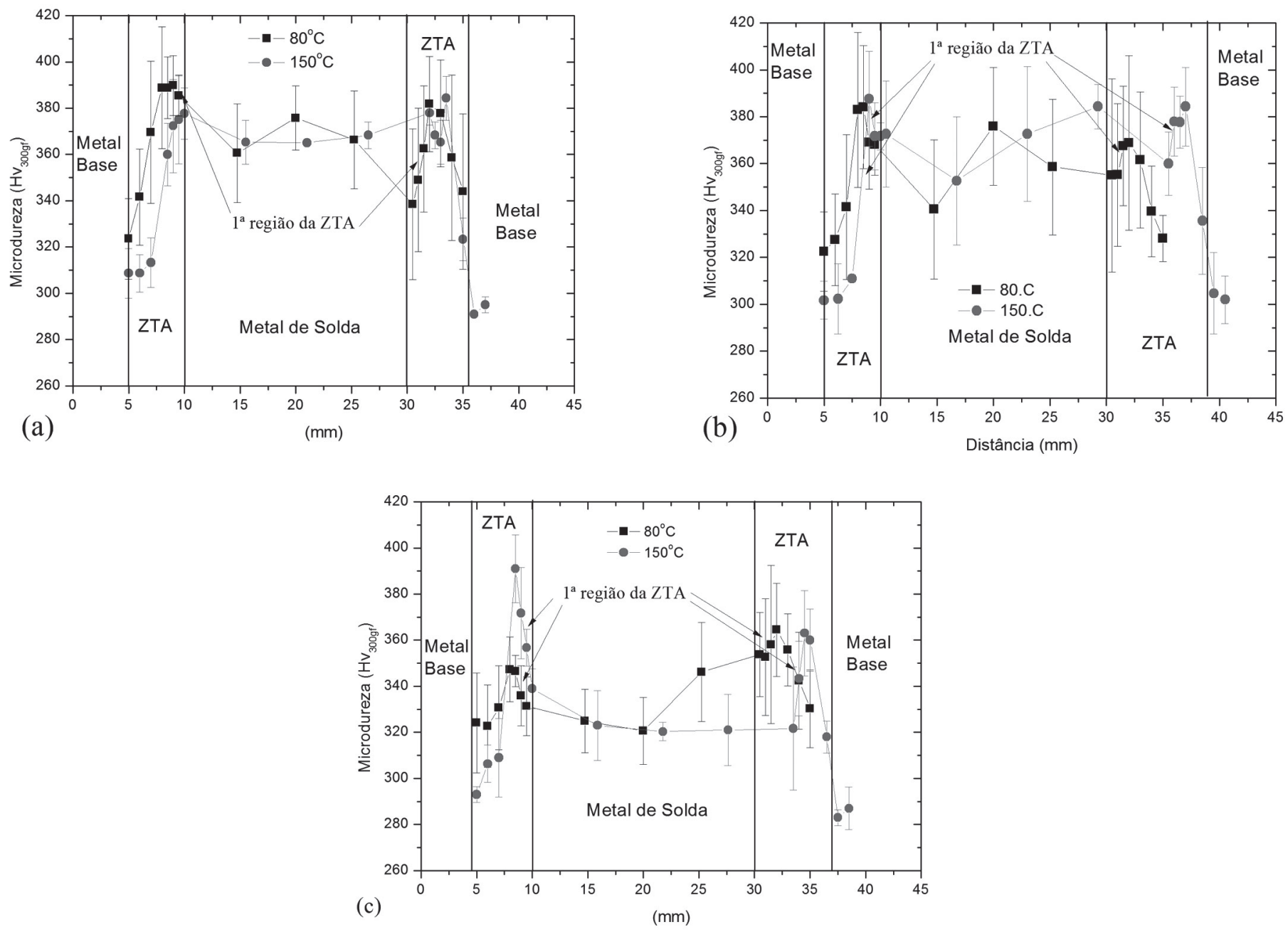

Figura 7. Perfil de microdureza das uniões soldadas com o aço AWS410 NiMo em diferentes temperaturas interpasse. Região superior (a), região central (b) e região inferior (c).

ferrita $\delta$ no campo monofásico, enquanto que para a temperatura mais baixa a maior taxa de resfriamento reduziu o tempo de permanência a elevadas temperaturas promovendo a formação de ferrita $\delta$ principalmente no campo bifásico. Resultados de ensaio de tenacidade a fratura em aços inoxidáveis martensíticos macios indicaram que um aumento da quantidade de ferrita $\mathrm{d}$ leva a uma redução na tenacidade ao impacto destes aços [14], entretanto a formação de ferrita $d$ no campo bifásico não afeta significativamente a tenacidade ao impacto da ZTA, quando comparado com a mesma microestrutura sem ferrita d [11].

Os perfis de dureza das juntas soldadas, visualizadas na Figura 7 , indicam de maneira geral, que a dureza é menor nas camadas inferiores para ambas as temperaturas de interpasse, e semelhante nas regiões intermediária e superior. Este comportamento reflete o revenimento, observado durante a avaliação microestrutural, imposto pelos repetidos ciclos térmicos nos cordões depositados

Observa-se também uma variação de dureza nas regiões central e superior ao longo da seção transversal dos cordões de solda, que poderiam estar relacionados ao fato das camadas de cordões não estarem alinhados, promovendo variação dos ciclos térmicos que estariam afetando a dureza de maneira irregular.
Em relação à microdureza da ZTA observou-se um aumento da dureza da $1^{\mathrm{a}}$ região da ZTA, região de precipitação de ferrita $\mathrm{d}$, para a $2^{\mathrm{a}}$ região da ZTA, onde ocorre a formação de martensita não revenida, é observada para ambas as temperaturas de interpasse, este comportamento ocorre pela redução na dureza com a precipitação de ferrita d [13]. É observado um aumento mais significativo de dureza do metal de solda para a ZTA na região inferior do corpo de prova da amostra soldada com $80^{\circ} \mathrm{C}$ de temperatura interpasse, provavelmente decorrente do processo de revenimento do metal de solda. As demais regiões superior e central apresentam um comportamento muito similar entre as amostras.

\subsection{Análise da tenacidade ao impacto e propagação de trinca por fadiga}

Os resultados de ensaio de tenacidade ao impacto Charpy são visualizados na Figura 8 . As amostras retiradas da união soldada com controle de temperatura de interpasse de $80^{\circ} \mathrm{C}$ apresentaram um valor médio de $165 \mathrm{~J}$, enquanto que as amostras retiradas da união soldada com $150^{\circ} \mathrm{C}$ de temperatura interpasse 
apresentaram um valor médio de 128J.

Os valores de tenacidade ao entalhe foram superiores aos observados na literatura, Tabela 1. Estes resultados indicam que o processo GTAW apresenta-se como uma excelente alternativa para o reparo do aço CA6NM, porém há nitidamente uma influência significativa da temperatura de interpasse. Ao analisar trabalhos anteriores com este material, e considerando os resultados do presente trabalho, verifica-se que quanto menor a temperatura de interpasse, maior a tenacidade obtida.

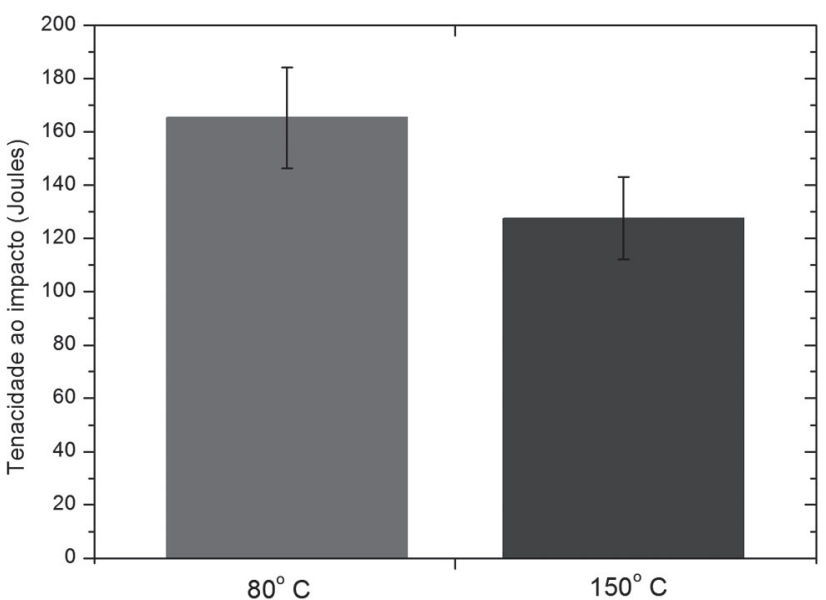

Figura 8. Tenacidade ao impacto do aço AWS410 NiMo em diferentes temperaturas interpasse.

As possíveis causas para este interessante resultado obtido no presente trabalho seriam relacionados aos seguintes fatores:

- Variação na morfologia da ferrita $\delta$, que na temperatura de interpasse de $80^{\circ} \mathrm{C}$ apresenta-se intergranular e pouco alinhada, o que favorece uma maior tenacidade em relação a morfologia vermicular observada nas amostras com interpasse de $150^{\circ} \mathrm{C}$, indicando resultados semelhantes aos observados em trabalhos anteriores [11-12];

- Ocorrência de um certo grau de revenimento observado na região inferior do corpo de prova, devido aos cordões subsequentes;

- A ocorrência de um refino da microestrutura nas regiões inferior e central dos corpos de prova, melhorando a sua tenacidade;

A redução na tenacidade ao impacto com o aumento do teor de ferrita d também é confirmado por [14], onde é descrito que um aumento no teor de ferrita d, de $4 \%$ para $8 \%$ para o aço CA6NM, leva a uma redução na tenacidade a $0^{\circ} \mathrm{C}$, de $190 \mathrm{~J}$ para aproximadamente 110J. Entretanto o autor descreve que a principal influência do teor de ferrita d está na alteração da faixa de transição dúctil-frágil, sem alterar as energias de impacto dos patamares superior e inferior do aço CA6NM. Os resultados observados em [14] são relativamente próximos aos observados no metal de solda obtidos neste trabalho

Como forma de se verificar o comportamento à fadiga dos depósitos analisados, efetuou-se ensaios de propagação de trincas em corpos de prova retirados dos depósitos soldados. $\mathrm{Na}$ Figura 9 verificam-se as velocidades de crescimento de trinca com a variação do $\mathrm{D} K$ para as amostras localizadas no metal de solda em relação à do aço CA6NM, enquanto que na Figura 10 observa-se o comportamento do avanço de trinca localizada na ZTA destas amostras.

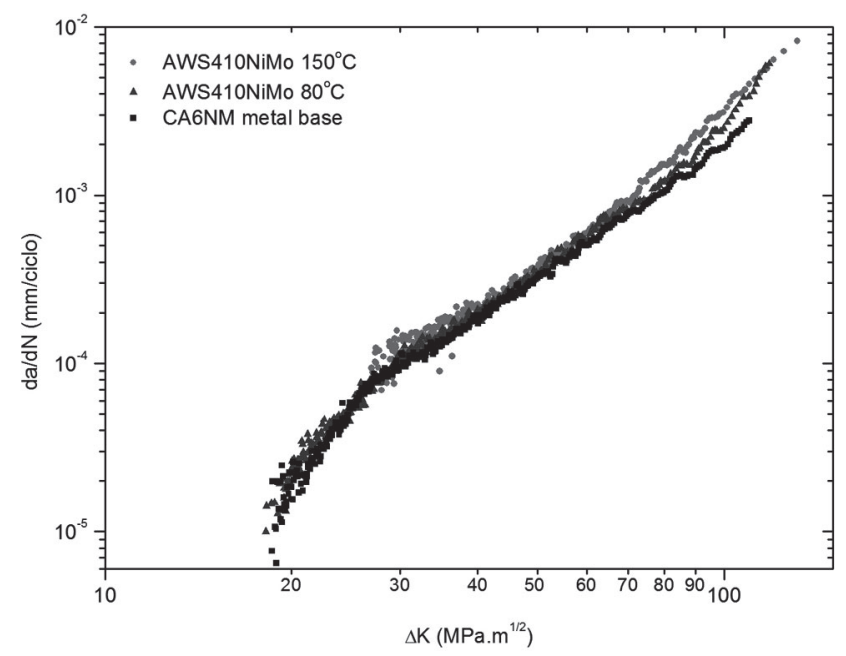

Figura 9. Velocidade de propagação de trincas vs. Fator de intensidade de tensão (da/dN/DK) dos metais de solda testados em comparação com o metal base CA6NM.

Pelos resultados obtidos foi possível identificar uma pequena variação no comportamento à propagação de trincas por fadiga com as diferentes temperaturas interpasse utilizadas. As velocidades de propagação de trincas por fadiga das amostras soldadas por TIG utilizando temperatura interpasse de $150^{\circ} \mathrm{C}$ foram levemente superiores à do CA6NM e das amostras soldadas com controle de temperatura interpasse de $80^{\circ} \mathrm{C}$, Tabela 5 .

Tabela 5. Constantes C e m obtidas no ensaio de propagação de trinca por fadiga.

\begin{tabular}{|c|c|c|}
\hline & $\mathrm{C}$ & $\mathrm{m}$ \\
\hline Metal base & $1,224.10^{-8}$ & 2,63 \\
\hline AWS410_150 ${ }^{\circ} \mathrm{C}$ & $9,0797.10^{-9}$ & 2,73 \\
\hline AWS410_80 ${ }^{\circ} \mathrm{C}$ & $1,2392.10^{-8}$ & 2,62 \\
\hline ZTAAWS410_150 ${ }^{\circ} \mathrm{C}$ & $3,553.10^{-9}$ & 2,87 \\
\hline ZTAAWS410_80 ${ }^{\circ} \mathrm{C}$ & $2,146.10^{-9}$ & 3,04 \\
\hline FCAW410NiMo $150^{\circ} \mathrm{C}[15]$ & $2,47.10^{-10}$ & 3,80 \\
\hline
\end{tabular}

A partir dos resultados apresentados na Tabela 5 observa-se que o metal de solda apresenta propriedades à fadiga semelhantes ao do metal base, independente da temperatura de interpasse utilizada. Os resultados obtidos neste trabalho foram muito superiores aos obtidos em soldagem com arame tubular FCAW (flux cored arc welding), devido principalmente à redução na quantidade de inclusões de escória [15]. 


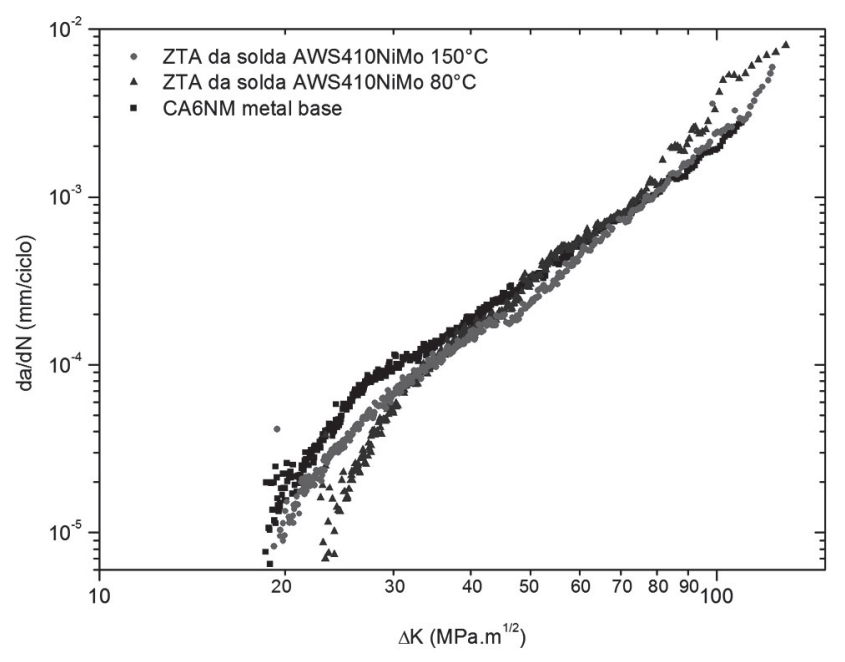

Figura 10. Velocidade de propagação de trincas vs. Fator de intensidade de tensão (da/dN/DK) da ZTA em comparação com o metal base CA6NM.

A maior velocidade de propagação de trinca da amostras soldada com $150^{\circ} \mathrm{C}$ de temperatura de pré-aquecimento pode ser atribuída às alterações na precipitação de ferrita $\delta$, provavelmente decorrente da formação alongada da ferrita d originada no campo monofásico, enquanto que a formação de ferrita $d$ no campo bifásico não levou a uma alteração significativa do comportamento a fadiga do material. Segundo observado na literatura, em aço inoxidável austenítico 304L, a interface ferrita $\mathrm{d} /$ matriz austenita g é um sítio preferencial de iniciação de trinca por fadiga, afetando a vida a fadiga [16].

Valores semelhantes de redução na inclinação de reta com a diminuição na temperatura de interpasse foram observados em ensaios utilizando soldagem MIG/MAG e arame AWS410NiMo em metal base ferrítico SA240-T410-S [17].

As amostras localizadas na ZTA apresentaram coeficiente $m$ superior à do aço CA6NM e ao do metal de solda, Tabela 5, independente da temperatura interpasse utilizada, indicando que o aumento de dureza decorrente do processo de reaquecimento, diminuiu a resistência à propagação de trincas por fadiga, comportamento este observado na literatura [15]. Deve-se observar que a amostra localizada na ZTA da amostra soldada com temperatura de interpasse de $80^{\circ} \mathrm{C}$ apresentou uma maior velocidade de propagação de trinca por fadiga que a amostra soldada com interpasse de $150^{\circ} \mathrm{C}$, sendo que os motivos que levam a este comportamento não ficaram bem claros, pois em termos de microestrutura e de dureza as ZTAs, as amostras apresentam-se muito semelhantes.

\section{Conclusões}

Após o estudo da influência da temperatura interpasse na soldagem TIG, para as condições avaliadas, foi possível concluir que:

- Foi possível obter depósitos soldados isentos de poros e trincas a partir do processo de soldagem GTAW e com microestrutura e tenacidade adequadas, apesar de não existir norma específica para regiões soldadas e para esta classe de aço.

- Observou-se nos depósitos obtidos por soldagem TIG que a adoção de diferentes temperaturas de interpasse alteraram a formação de ferrita $\delta$ do metal de solda durante $o$ reaquecimento gerado pelo passe subsequente. Foi observado a formação de ferrita $\delta$ de forma intergranular, na amostra soldada com temperatura interpasse de $80^{\circ} \mathrm{C}$, enquanto que na amostra soldada a $150^{\circ} \mathrm{C}$ a formação de ferrita $\delta$ no campo monofásico ocorre entre placas de austenita de Widmanstätten.

- A alteração na formação de ferrita $\delta$ e na microestrutura gerada pela soldagem em diferentes temperaturas de controle interpasse não alteraram significativamente a microdureza da região soldada e ZTA, entretanto a adoção de $80^{\circ} \mathrm{C}$ como temperatura de interpasse promoveu um aumento de 128 para $165 \mathrm{~J}$ na tenacidade ao impacto da amostra soldada com AWS 410NiMo.

- Observou-se uma redução na taxa de crescimento de trinca na amostra soldada com temperatura de interpasse de $80^{\circ} \mathrm{C}$, em comparação com a amostra soldada a $150^{\circ} \mathrm{C}$, acompanhando os resultados observados de tenacidade ao impacto.

\section{Agradecimentos}

Os autores agradecem à COPEL suporte financeiro, a Voith Hydro pelo envio do metal base CA6NM, ao Lactec pela utilização dos laboratórios de soldagem e ensaios mecânicos.

\section{Referências Bibliográficas.}

[1] HUTH, HANS-JÖRG, Fatigue design of hydraulic turbine runners, 2005, 178p., Tese (Doutorado) - Department of Engineering Design and Materials, Norwegian University of Science and Technology, Trondheim, Norway.

[2] BILMES, P. D.; SOLARI, M.; LlORENTE, C. L, Characteristics and Effects of Austenite Resulting From Tempering of $13 \mathrm{Cr}$ - NiMo Martensitic Steel Weld Metals, Materials Characterization, 46, p. 285-296, 2001.

[3] FOLKHARD, E., Welding Metallurgy of Stainless Steels, Springer-Verlag Wien New York, 1988.

[4] AKHTAR, A., BRODIE, N. W., Field welding large turbine runners, Water Power \& Dam Construction, September, p. 4046, 1979.

[5] PEREIRA, S. A., Desenvolvimento de Procedimento de Reparo por Soldagem em Aços Inoxidáveis Martensíticos com Metal de Adição Similar sem TTP, 2000, Dissertação (Mestrado), Programa de Pós Graduação em Engenharia Mecânica, UFSC, Florianópolis, Santa Catarina.

[6] PRADO, E. M., Influência das variáveis do processo MIG/ MAG Convencional e MIG Pulsado nas propriedades mecânicas de juntas soldadas com arame ER410NiMo, 2004, Dissertação (Mestrado), Programa de Pós-graduação em Engenharia Mecânica, UFPR, Curitiba, Paraná 
[7] ASTM E 23-99, American Standard for Testing and Materials, ASTM: Standard Methods for Notched Bar Impact Testing of Metallic Materials, for Type A Charpy (simple beam) Impact Specimen

[8] AWS D1.1/D1.1M:2004 An American National Standard Structural Welding Code-Steel.

[9] ASTM E647-95a, American Standard for Testing and Materials, ASTM: Standard test method for measurement of fatigue crack growth rates.

[10] ASTM E384-99, American Standard for Testing and Materials, ASTM: Standard test method for microindentation hardness of materials.

[11] CARROUGE, D., Phase transformations in the heat-affected zone of low carbon $13 \% \mathrm{Cr}$ stainless steels, 2002, 185p., Tese (Doutorado), Materials Science and Metallurgy Department, Cambridge University.

[12] WOOllin, P., CARROUGE, D., Heat affected zone microstructures in supermartensitic stainless steels, Conference on Super martensitic Stainless Steels, Bruxelas, Bélgica, 3 a 4 de outubro de 2002.

[13] THIBAULT, D., BOCHER, P., THOMAS, M., Residual stress and microstructure in welds of $13 \% \mathrm{Cr} 4 \% \mathrm{Ni}$ martensitic stainless steel, Journal of Materials Processing Technology, 209, p.2195-2202, 2009.

[14] WANG, P., LU, S.P., XIAO, N.M., LI, D.Z., LI, Y.Y., Effect of delta ferrite on impact properties of low carbon $13 \mathrm{Cr}-4 \mathrm{Ni}$ martensitic stainless steel, Materials Science and Engineering A, 527, p. 3210-3216, 2010.

[15] PUKASIEWICZ, A.G.M., HENKE, S.L., CASAS, W.J.P., Influência do Tratamento Térmico Pós-Soldagem na Propagação de Trincas por Fadiga em Juntas Soldadas do Aço Inoxidável Martensítico Macio CA6NM, Soldagem \& Inspeção, vol.10, n 3, p.109-116, 2005.

[16] Rho, S. B., Hong, H.U., Nam, S.W., The effect of d ferrite on fatigue cracks in 304L steels, International Journal of Fatigue, 22, p. 683-690, 2000.

[17] SÁNCHEZ-CABRERA, V.M., et.al., Effect of preheating temperature and filler metal type on the microstructure, fracture toughness and fatigue crack growth of stainless steel welded joints, Materials Science and Engineering A, 452-453, p. 235243, 2007. 